\title{
The Optimization of Maize yield Production Using Simplex Lattice Design for Third Degree Mixture Model
}

\author{
Joseph Kipyegon.Cheruiyot ${ }^{1}$, Joseph K. Arap Koske ${ }^{2}$ and John Mutiso \\ Department of Statistics and Computer Science, \\ School of Biological and Physical science, Moi University, Eldoret Kenya \\ Correspondent Email: jcheruiyot34@gmail.com
}

\begin{abstract}
This study involved mixture experiment for fertilizer components in maize crop production. Researchers in agriculture have conducted research on maize plants with different levels of single fertilizers with a view of obtaining an appropriate amount for optimal yield. However, studies based on fertilizer blending are not very common. This has left farmers with no option other than to continue applying fertilizer in random proportions that may not guarantee the optimal yield with respect to fertilizer components available. The objectives was to determine appropriate statistical models expressing the maize yield as response variable and to evaluate optimal sets of mixture of fertilizer components that could maximize the response variables of interest. Di-Ammonium Phosphate (DAP), Poultry manure (guano), Sheep manure, and Farmyard manure were the four independent variables to optimize the response value of the maize yield. Mixture experiments entail the blending of these components to determine if synergism exists in the mixture or blends of these fertilizer components. The statistical model formulated for the maize yield demonstrates the effects of each component and the interaction with other components displaying the trend of the response parameter. From the model, it can be concluded that farmyard manure and poultry manure have greater effect on the production of maize yield and hence, this study conclusively attained the optimal conditions of 6.67 tons ha ${ }^{-1}$ of farmyard manure mixed with 1.3467 tons $^{-1} \mathrm{of}^{-1}$ poultry manure. Under these conditions, the farmer achieves maximum output of 12.17 tons ha $^{-1}$ of maize yield. The study upholds that mixture experiments are appropriate in modeling agricultural production involving various independent parameters that produces synergetic effect on the output parameter.
\end{abstract}

KEY WORDS: Maize yield; Fertilizer; Model; Mixture experiment; Simplex Lattice Design.

DOI: $10.7176 / \mathrm{MTM} / 9-7-07$

Publication date: July $31^{\text {st }} 2019$

\subsection{INTRODUCTION}

Maize is a food crop commonly known as corn with scientific name Zea mays. It is used as a household stable food in most African countries and is produced widely for subsistence as well as cash crop. The maize crop is mostly grown as a food crop but the challenge is that the production of this food crop does not match with the high crop demand. It has been recognized that agriculture production in Kenya East Africa is characterized by a negative nutrients imbalance (De Jager et al 1998). Nonetheless, the low production that has caused the deficit is attributed to a number of factors including the diminishing land set for agricultural use due to increasing demand from the ever increasing population, poor farming methods, high cost of fertilizers and inability for farmers to embrace adoptive research among others (KARI-Njoro annual report, 2013). In addition, the low production is due to deteriorating soil fertility caused by the over dependence on application of certain synthetic fertilizers. Improving or enhancing maize yield per acre therefore, is a welcome move since maize deficit in the country is posing a big challenge.

Scientific research methods in various disciplines are tools that aid in addition of scientific knowledge with a view of improving the livelihood of the society. In agricultural production, there are situations where production is influenced by a set of conditions that needs to be balanced to maximize or minimize the desired response. A response surface methodology therefore is one of those tools that need extensive application in optimizing the desired response by varying the ingredients or components that constitute the independent variables. This new approach can supplement the traditional design of experiment's methods commonly used in this field particularly in maize research.

Mixture experiments are commonly encountered in several fields, including the food, chemical, pharmaceutical, engineering and consumer products among many others. For mixture experiments, the design factors are the proportions of the components under study that sum to a constant, and response variable depends on these proportions. A number of mixtures experimental designs have been formulated but the most commonly applied is simplex-lattice design. It takes the shape of a triangle with the pure blends being located at the vertices of the triangle for a case of a three-component mixture. Interior points give blends of all the components while data 
collected at the midpoint of the edges of the triangular surface gives the response for the binary blends. However, for a four-component mixture, it takes the form of a tetrahedron.

According to Scheffe' (1958), the Simplex Lattice Design $\{\mathrm{q}, \mathrm{m}\}$ is defined as a design which uniformly covers the factor space with each factor having $\mathrm{m}+1$ equally spaced values from 0 to 1 such that $\sum_{i=0}^{q} x_{i}=1$.

For instance, a polynomial of degree $\mathrm{m}$ in $\mathrm{q}$ components over a simplex-lattice is referred to as a $\{\mathrm{q}, \mathrm{m}\}$ simplex-lattice. It consists of $\mathrm{m}+1$ equally spaced component proportions. Each component assumes the values from 0 to 1 given as,

$$
x_{i}=0, \frac{1}{m}, \frac{2}{m}, \ldots ., 1
$$

The $\{\mathrm{q}, \mathrm{m}\}$ Simplex-lattice consists of all possible mixture combinations of the components where the proportions for each component are used. However, the $\{4,3\}$ simplex-lattice design comprise of 20 design points. Where $\mathrm{x}_{\mathrm{i}}=0,1 / 3,2 / 3$ and 1 since $\mathrm{m}=3$.

\subsection{MATERIAL AND METHODS}

The selection of experimental design is normally influenced by the consideration of many factors but mainly those that are geared towards the attainment of the set objectives. However, design with small number of runs, if it provides enough information on the coefficients are cost effective as compared to designs with large number of runs. One other factor to be considered in the design selection is the prediction capacity of the design. Scaled prediction variance has been suggested as a measure of prediction variance (Muriithi 2017).

\subsection{Field experiment}

In order to generate credible data from the mixture experiment, a simplex lattice design with four factors was adopted. The effects of the four fertilizer components on the maize yield were investigated by varying mixture proportion simultaneously and maintaining the amount constant (Scheffe' 1958).

Table 1. Amount of fertilizer applied per hectare.

\begin{tabular}{lll}
\hline Fertilizer type & $\begin{array}{l}\text { Amount per } \\
\text { Hectare in Tons }\end{array}$ & $\begin{array}{l}\text { Amount per stand as single } \\
\text { component }\end{array}$ \\
\hline Farmyard manure & 20.00 & $372 \mathrm{~g}$ \\
D.A.P & 0.3120 & $5.8 \mathrm{~g}$ \\
Sheep manure & 10.00 & $185 \mathrm{~g}$ \\
Poultry manure & 2.020 & $37 \mathrm{~g}$ \\
\hline
\end{tabular}

The independent variable to optimize the response of interest maize grain (yield) were Farmyard manure $\left(\mathrm{x}_{1}\right)$, Di-Ammonium Phosphate DAP $\left(\mathrm{x}_{2}\right)$, Sheep manure $\left(\mathrm{x}_{3}\right)$ and Poultry manure $\left(\mathrm{x}_{4}\right)$. A mixture design of four components third order comprising of 20 possible blends of the four components was adopted. These design points are the design coordinates that are arranged so that all combination of the factor levels are tested and each of the factors in the design can take values value $x_{i}=0, \frac{1}{3}, \frac{2}{3}, 1$ with the restriction $\sum_{\mathrm{i}=1}^{4} \mathrm{x}_{\mathrm{i}}=1$. The statistical design is referred to as $\{4,3\}$ simplex lattice design and the coded design points with corresponding response variables are as shown in table 2 . 
Table 2. List of Simplex lattice design coded components

\begin{tabular}{llllll}
\hline $\mathbf{N}$ & $\mathbf{X}_{\mathbf{1}}$ & $\mathbf{X}_{\mathbf{2}}$ & $\mathbf{X}_{\mathbf{3}}$ & $\mathbf{X}_{\mathbf{4}}$ & Response \\
\hline 1 & 1 & 0 & 0 & 0 & $\mathrm{Y}_{1}$ \\
2 & 0 & 1 & 0 & 0 & $\mathrm{Y}_{2}$ \\
3 & 0 & 0 & 1 & 0 & $\mathrm{Y}_{3}$ \\
4 & 0 & 0 & 0 & 1 & $\mathrm{Y}_{4}$ \\
5 & $1 / 3$ & $2 / 3$ & 0 & 0 & $\mathrm{Y}_{122}$ \\
6 & $1 / 3$ & 0 & $2 / 3$ & 0 & $\mathrm{Y}_{133}$ \\
7 & $1 / 3$ & 0 & 0 & $2 / 3$ & $\mathrm{Y}_{144}$ \\
8 & 0 & $1 / 3$ & $2 / 3$ & 0 & $\mathrm{Y}_{233}$ \\
9 & 0 & $1 / 3$ & 0 & $2 / 3$ & $\mathrm{Y}_{244}$ \\
10 & 0 & 0 & $1 / 3$ & $2 / 3$ & $\mathrm{Y}_{344}$ \\
11 & $2 / 3$ & $1 / 3$ & 0 & 0 & $\mathrm{Y}_{112}$ \\
12 & $2 / 3$ & 0 & $1 / 3$ & 0 & $\mathrm{Y}_{113}$ \\
13 & $2 / 3$ & 0 & 0 & $1 / 3$ & $\mathrm{Y}_{114}$ \\
14 & 0 & $2 / 3$ & $1 / 3$ & 0 & $\mathrm{Y}_{223}$ \\
15 & 0 & $2 / 3$ & 0 & $1 / 3$ & $\mathrm{Y}_{224}$ \\
16 & 0 & 0 & $2 / 3$ & $1 / 3$ & $\mathrm{Y}_{334}$ \\
17 & $1 / 3$ & $1 / 3$ & $1 / 3$ & 0 & $\mathrm{Y}_{123}$ \\
18 & $1 / 3$ & $1 / 3$ & 0 & $1 / 3$ & $\mathrm{Y}_{124}$ \\
19 & $1 / 3$ & 0 & $1 / 3$ & $1 / 3$ & $\mathrm{Y}_{134}$ \\
20 & 0 & $1 / 3$ & $1 / 3$ & $1 / 3$ & $\mathrm{Y}_{234}$ \\
\hline
\end{tabular}

\subsection{Statistical Model}

According to Cornell (1990), the first and the second -degree polynomial are adequate to model the response surface. However, for better precision and inclusiveness of more components, the third -degree polynomial that is expressed in terms of the response variable $\mathrm{y}$ is as stated below.

$$
y=\sum_{i=1}^{4} \alpha_{i} x_{i}+\sum_{\substack{j \\ i<j}}^{4} \sum_{i}^{4} \alpha_{i j} x_{i} x_{j}+\sum_{\substack{k \\ i<j<k}}^{4} \sum_{j}^{4} \sum_{i}^{4} \alpha_{i j k} x_{i} x_{j} x_{k}
$$

Where, $\alpha_{i}, \alpha_{i j}$ and $\alpha_{i j k}$ are parameters or coefficients of interest and $\mathrm{x}_{1}, \mathrm{x}_{2}, \mathrm{x}_{3}$ and $\mathrm{x}_{4}$ represents the input variables (independent variables). The model above referred as special cubic model or simplex-centroid model is preferred over the lower-degree models because the terms in the special cubic model not only provide a measure of each of pure blend, but provide measures of binary blends and a measure of the three-component blend as well.

\subsection{Analysis of the model.}

In order to check for the model adequacy and fitness, ANOVA table, model summary statistics and test of normality were employed. ANOVA is a statistical tool that involves partitioning the total sum of squares into sum of squares due to regression or blends and sum of squares due to residuals. The F-statistics was used for testing model adequacy and in identification of statistically significant fertilizer blends. To measure the amount of variation explained by the model, adjusted coefficient of determination (adjusted R square) was computed as shown.

\subsection{Field Experiment (Data source)}

$$
\mathrm{R}_{\mathrm{A}}^{2}=1-\frac{\mathrm{SSE} /(\mathrm{N}-\mathrm{p})}{\mathrm{SST} /(\mathrm{N}-1)}
$$

The research was done at University of Kabianga research and teaching farm. The identified field was cultivated in readiness for planting. It was then subdivided into 20 plots of size $2 \mathrm{~m}$ by $2.5 \mathrm{~m}$ each; with each plot, having 3 rows of 10 stands (holes). The optimal maize seeds spacing used was $0.75 \mathrm{M}$ inter-row and $0.25 \mathrm{M}$ intra-row. Prior to plantation season, the necessary laboratory tests to ascertaining the manure ingredients were carried out. In addition, several core soil samples were taken randomly from the plot for laboratory analysis. Hence, the estimation of fertilizer application required per hectare was established based on soil and manure analyses test results. Having done the necessary agronomic practices certified maize seeds (Hybrid628) were planted. 


\subsection{RESULTS AND DISCUSSION}

\subsection{Experimental data.}

Using Simplex lattice design, the following results were recorded as obtained from the field experiment.

Table 3. Design matrix and corresponding response variables.

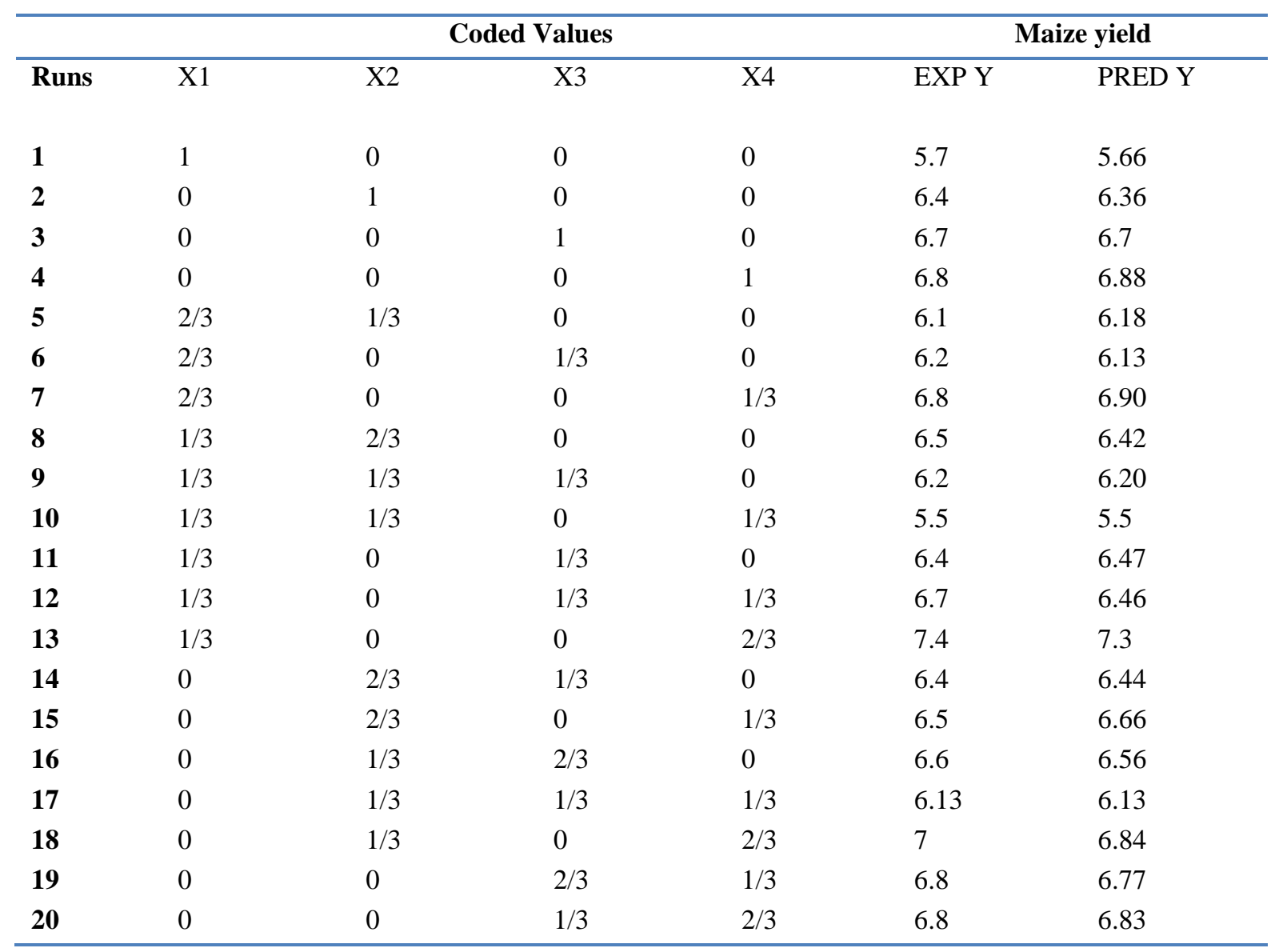

Table 3 displays the dependent variables and resultant response variable together with predicted response values. The coded variables $\mathrm{x}_{\mathrm{i}}$, was provided as $0 \leq x_{i} \leq 1$ and $\sum_{i} x_{i}=1$ and the dependent variables that is, the response maize grains $(\mathrm{Y})$ were given in Kilograms corrected to two decimal places. With the application of one way, analyze of variance, the effects of fertilizer components on maize yield were considered significant at $5 \%$ confident interval. Data analysis was done using statistical package "design expert version 11".

The study sought to determine the most suitable statistical model that best fit the maize yield data as obtained from the experiment. The summary of the analysis for model suitability was as displayed in table 4 .

Table 4: Model summary statistics

\begin{tabular}{llllll}
\hline Source & Std. Dev. & $\mathbf{R}^{2}$ & $\begin{array}{l}\text { Adjusted } \\
\mathbf{R}^{\mathbf{2}}\end{array}$ & PRESS & \\
\hline Special Cubic & 0.1365 & 0.9694 & 0.903 & $*$ & Suggested \\
\hline
\end{tabular}

Table 4 above shows the summary statistics associated with third- degree polynomial model (special cubic) of this study having a coefficient of determination of 0.903 . The coefficient of determination adjusted $\mathrm{R}$ squared is the percentage of variation that is explained by the components in the model. In this case, $90.3 \%$ of the variation in the maize yield was explained by the components in the model. Therefore, this study considered special cubic model fit for prediction of the maize grain production. 


\subsection{Fitting a statistical model for the maize yield}

The data obtained from the experiment were analyzed and the coefficients of the model were formulated according to the simplex lattice coded third-degree regression polynomial. The coefficients, standard error and Pvalues were presented as follows in Table 5

Table 5. Coefficients in Terms of Coded Factors on maize yield

\begin{tabular}{llll}
\hline Variable & Estimates & Std. Error & P-value \\
\hline $\mathbf{X}_{\mathbf{1}}$ & 5.66 & 0.1269 & $\mathbf{0 . 0 0 0 8}$ \\
$\mathbf{X}_{\mathbf{2}}$ & 6.36 & 0.1269 & $\mathbf{0 . 0 0 0 8}$ \\
$\mathbf{X}_{\mathbf{3}}$ & 6.7 & 0.1269 & $\mathbf{0 . 0 0 0 8}$ \\
$\mathbf{X}_{\mathbf{4}}$ & 6.88 & 0.1269 & $\mathbf{0 . 0 0 0 8}$ \\
$\mathbf{X}_{\mathbf{1}} \mathbf{X}_{\mathbf{2}}$ & 1.3 & 0.6002 & 0.0737 \\
$\mathbf{X}_{\mathbf{1}} \mathbf{X}_{\mathbf{3}}$ & 0.5318 & 0.6002 & 0.4097 \\
$\mathbf{X}_{\mathbf{1}} \mathbf{X}_{\mathbf{4}}$ & 3.73 & 0.6002 & $\mathbf{0 . 0 0 0 8}$ \\
$\mathbf{X}_{\mathbf{2}} \mathbf{X}_{\mathbf{3}}$ & -0.133 & 0.6002 & 0.832 \\
$\mathbf{X}_{\mathbf{2}} \mathbf{X}_{\mathbf{4}}$ & 0.5932 & 0.6002 & 0.3612 \\
$\mathbf{X}_{\mathbf{3}} \mathbf{X}_{\mathbf{4}}$ & 0.0511 & 0.6002 & 0.9349 \\
$\mathbf{X}_{\mathbf{1}} \mathbf{X}_{\mathbf{2}} \mathbf{X}_{\mathbf{3}}$ & -6.2 & 4.45 & 0.2127 \\
$\mathbf{X}_{\mathbf{1}} \mathbf{X}_{\mathbf{2}} \mathbf{X}_{\mathbf{4}}$ & -38.47 & 4.45 & $\mathbf{0 . 0 0 0 1}$ \\
$\mathbf{X}_{\mathbf{1}} \mathbf{X}_{\mathbf{3}} \mathbf{X}_{\mathbf{4}}$ & -5.22 & 4.45 & 0.2851 \\
$\mathbf{X}_{\mathbf{2}} \mathbf{X}_{\mathbf{3}} \mathbf{X}_{\mathbf{4}}$ & -15.45 & 4.45 & $\mathbf{0 . 0 1 3 2}$ \\
\hline
\end{tabular}

The coefficient estimate represents the expected change in response per unit change in factor value when all remaining factors are held constant. The study found that all linear components Farmyard $\left(\mathrm{X}_{1}\right), \mathrm{DAP}\left(\mathrm{X}_{2}\right), \operatorname{Sheep}$ manure $\left(\mathrm{X}_{3}\right)$ and Poultry manure $\left(\mathrm{X}_{4}\right)$ had significant effect on the maize yield with a common p-value equivalent to 0.0008 , which is less than 0.05 . This implies that for a unit increase in farmyard manure holding other factors constant; translate to an increase in maize yield by a factor 5.66. Similarly, for a unit increase for each of the other components (DAP, sheep manure and poultry manure) holding other factors constant in turns translates to an increase by a factor $6.36,6.7$ and 6.88 respectively. However, for the binary mixture components, the mixture of farmyard and poultry had a significant effect on the maize yield as portrayed by a $p$ - value $=0.008$ less than 0.05 . The mixture was found to have a positive effect on the yield by a factor 3.73 . The positive value indicates that there is a significant synergy between the farmyard manure and the poultry manure. In addition, the results indicate that the tertiary combination of mixtures (Farmyard manure, DAP and Poultry manure) and (DAP, Sheep manure and Poultry manure) have negative factor of 38.47 and 15.45 respectively. This implies that the three factor interactions are antagonistic and hence the negative effects on the maize yield.

The special cubic model obtained for the maize yield as a function of the independent variables was expressed as follows.

$$
\begin{aligned}
& Y=5.66 X_{1}+6.36 X_{2}+6.7 X_{3}+6.88 X_{4}+1.3 X_{1} X_{2}+0.5318 X_{1} X_{3}+3.73 X_{1} X_{4}-0.133 X_{2} X_{3} \\
& +0.5932 X_{2} X_{4}+0.0511 X_{3} X_{4}-6.2 X_{1} X_{2} X_{3}-38.47 X_{1} X_{2} X_{4}-5.22 X_{1} X_{3} X_{4}-15.45 X_{2} X_{3} X_{4}
\end{aligned}
$$

Where $\mathrm{Y}$ is the predicted response for maize grain (yield) and $\mathrm{X}_{\mathrm{i}}(\mathrm{i}=1,2,3,4)$ represent the control factors in the experimental data $(1=$ farmyard manure, $2=$ DAP. $3=$ sheep manure, $4=$ poultry manure $)$.

\subsection{Analysis of variance (ANOVA)}

In order to check the adequacy of the model, for the response variable (maize yield) in the experimental data at 95\% confidence level, Analysis of variance (ANOVA) was used. 
Table 6: ANOVA for the effect of fertilizers on maize yield.

\begin{tabular}{lllllll}
\hline Source & DF & SS & MSS & F-value & F-Critical & P-value \\
\hline Model & 13 & 3.54 & 0.2722 & 14.6 & 2.92 & 0.0017 \\
Linear Mixture & 3 & 1.43 & 0.4783 & 25.66 & 8.94 & 0.0008 \\
$\mathbf{X}_{\mathbf{1}} \mathbf{X}_{\mathbf{2}}$ & 1 & 0.0873 & 0.0873 & 4.68 & 5.99 & 0.0737 \\
$\mathbf{X}_{\mathbf{1}} \mathbf{X}_{\mathbf{3}}$ & 1 & 0.0146 & 0.0146 & 0.7851 & 5.99 & 0.4097 \\
$\mathbf{X}_{\mathbf{1}} \mathbf{X}_{4}$ & 1 & 0.7209 & 0.7209 & 38.68 & 5.99 & 0.0008 \\
$\mathbf{X}_{\mathbf{2}} \mathbf{X}_{\mathbf{3}}$ & 1 & 0.0009 & 0.0009 & 0.0491 & 5.99 & 0.832 \\
$\mathbf{X}_{\mathbf{2}} \mathbf{X}_{\mathbf{4}}$ & 1 & 0.0182 & 0.0182 & 0.9768 & 5.99 & 0.3612 \\
$\mathbf{X 3}_{\mathbf{X}}$ & 1 & 0.0001 & 0.0001 & 0.0073 & 5.99 & 0.9349 \\
$\mathbf{X}_{\mathbf{1}} \mathbf{X}_{\mathbf{2}} \mathbf{X}_{\mathbf{3}}$ & 1 & 0.0362 & 0.0362 & 1.94 & 5.99 & 0.2127 \\
$\mathbf{X}_{\mathbf{1}} \mathbf{X}_{\mathbf{2}} \mathbf{X}_{4}$ & 1 & 1.4 & 1.4 & 74.91 & 5.99 & 0.0001 \\
$\mathbf{X}_{\mathbf{1}} \mathbf{X}_{\mathbf{3}} \mathbf{X}_{\mathbf{4}}$ & 1 & 0.0257 & 0.0257 & 1.38 & 5.99 & 0.2851 \\
$\mathbf{X}_{\mathbf{2}} \mathbf{X}_{\mathbf{3}} \mathbf{X}_{\mathbf{4}}$ & 1 & 0.2252 & 0.2252 & 12.08 & 5.99 & 0.0132 \\
$\mathbf{R e s i d u a l}$ & 6 & 0.1118 & 0.0186 & & & \\
Total & 19 & 3.65 & & & & \\
\hline
\end{tabular}

The Model F-value of 14.60 implies the model is significant according to F-test with $95 \%$ of confidence, as the F-value of 14.60 is higher than F-critical $=2.92$. Further, the P-value=0.0017 is less than 0.0500 significant level, suggesting that model adequacy was met in this study. In addition, the linear components were also statistically significant with a P-value of $0.0008<5 \%$ significant level. The other statistically significant components in the model include the binary blend farmyard and Poultry manure $\left(\mathrm{X}_{1} \mathrm{X}_{4}\right)$, and other two tertiary blends. Values greater than 0.1000 indicate the model terms are not significant.

\subsection{Test for normality}

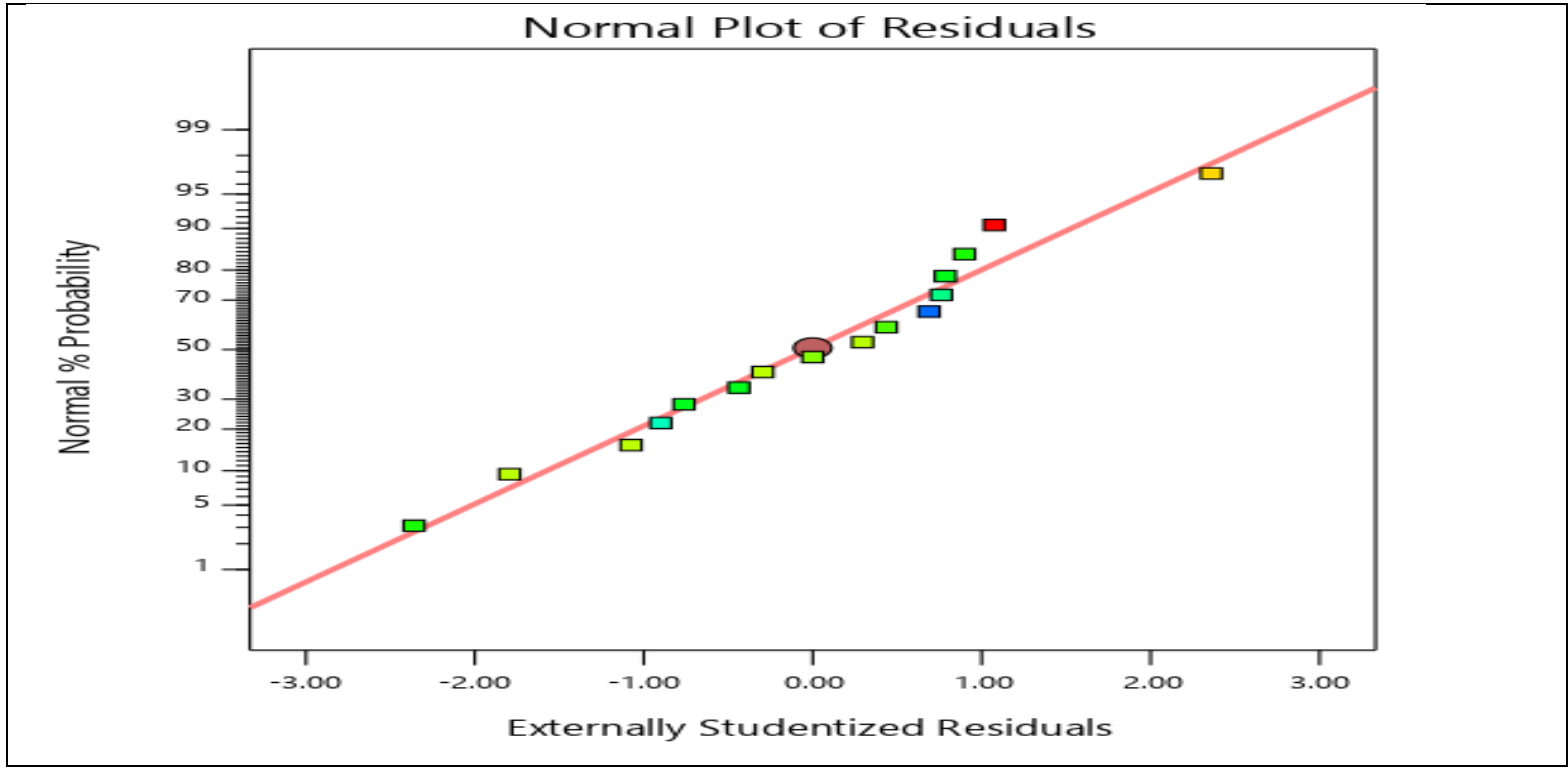

Figure 1. Normal probability plot of the residuals

Normal probability plot is a graphical technique for assessing whether or not a data set is approximately normally distributed. Departure from this straight line indicates departure from normality. In this case, the points are normally distributed as shown in the figure above where points are along the line of best fit. This implies that residuals portray a normal trend. 


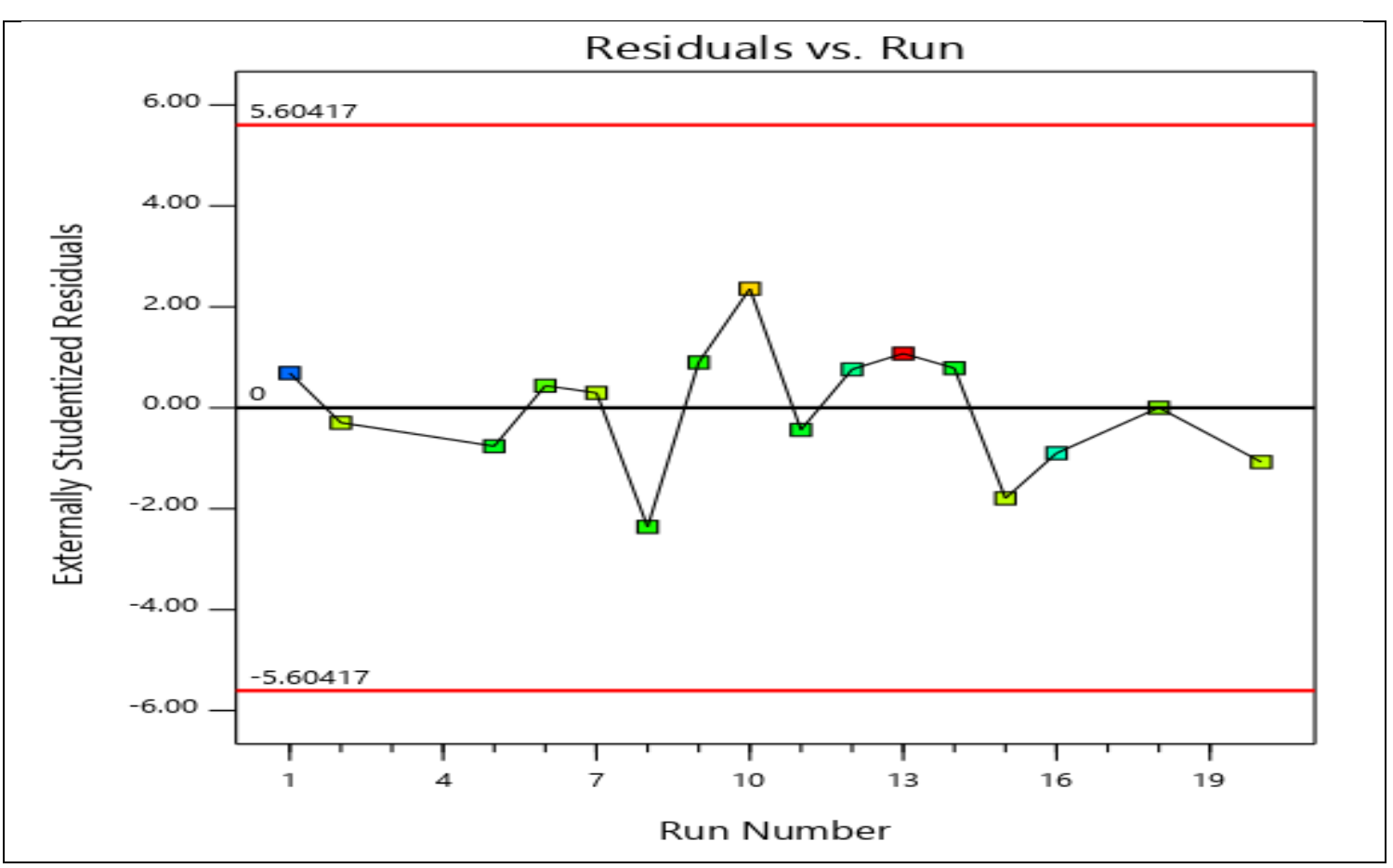

Figure .2: Plot for residuals against Runs

The plot in figure (2) does not exhibit a pattern or any particular trend but rather it portrays a random scatter of runs thus satisfying the assumption that the error term had constant variance.

\subsection{Model validation}

The graphical representation of predicted values for maize yield obtained from the model under study against the corresponding actual experimental response values is as shown in figure 2.

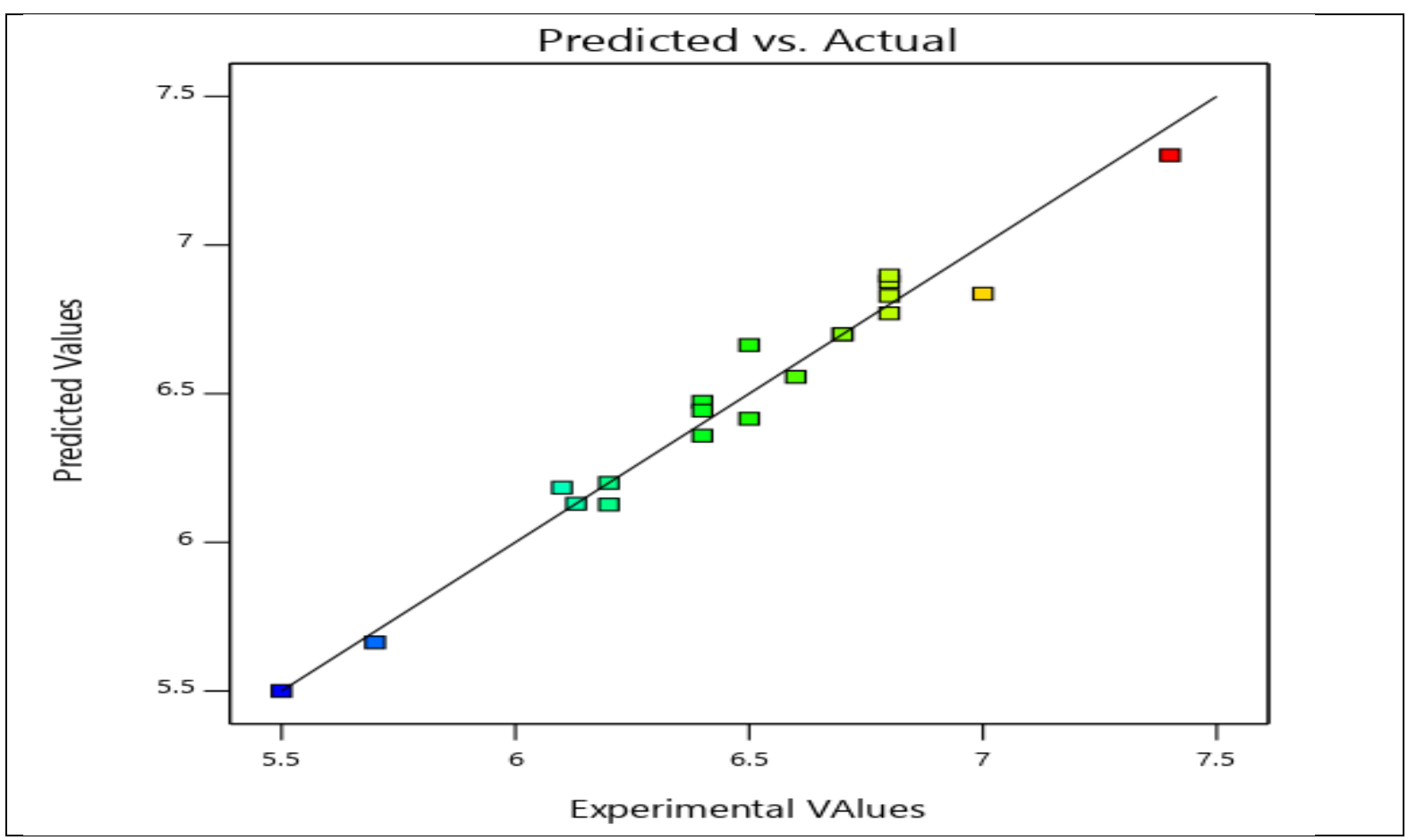

Figure 3: Predicted values versus experimental values of maize yield 
In figure 3, the plot of the line of the best fit indicates the predicted values or the trend line versus the actual experimental values. The graph shows a close correlation between the experimental response values and predicted values portrayed by the fact that most points are on the line of best fit. This close relationship between the predicted value and the actual value depicts the accuracy (fitness) of the model. In this study the close correlation in the comparison between both values is a clear indication that third order mixture model can be used to describe the relationship between the factors and the response variable the Maize yield.

\subsection{Optimal Conditions for Maize yield}

The objective was to determine the set of fertilizer components proportion that produces maximum maize yield. To identify the required optimal conditions, three-dimension graphs were plotted for the response variable $y$. However, since the study entails four factors, one factor was held constant at zero in turns to allow the study of the effect of the other three factors on response surface. Hence, the following figures show the response surfaces of maize yield with respect to different fertilizer component proportions.

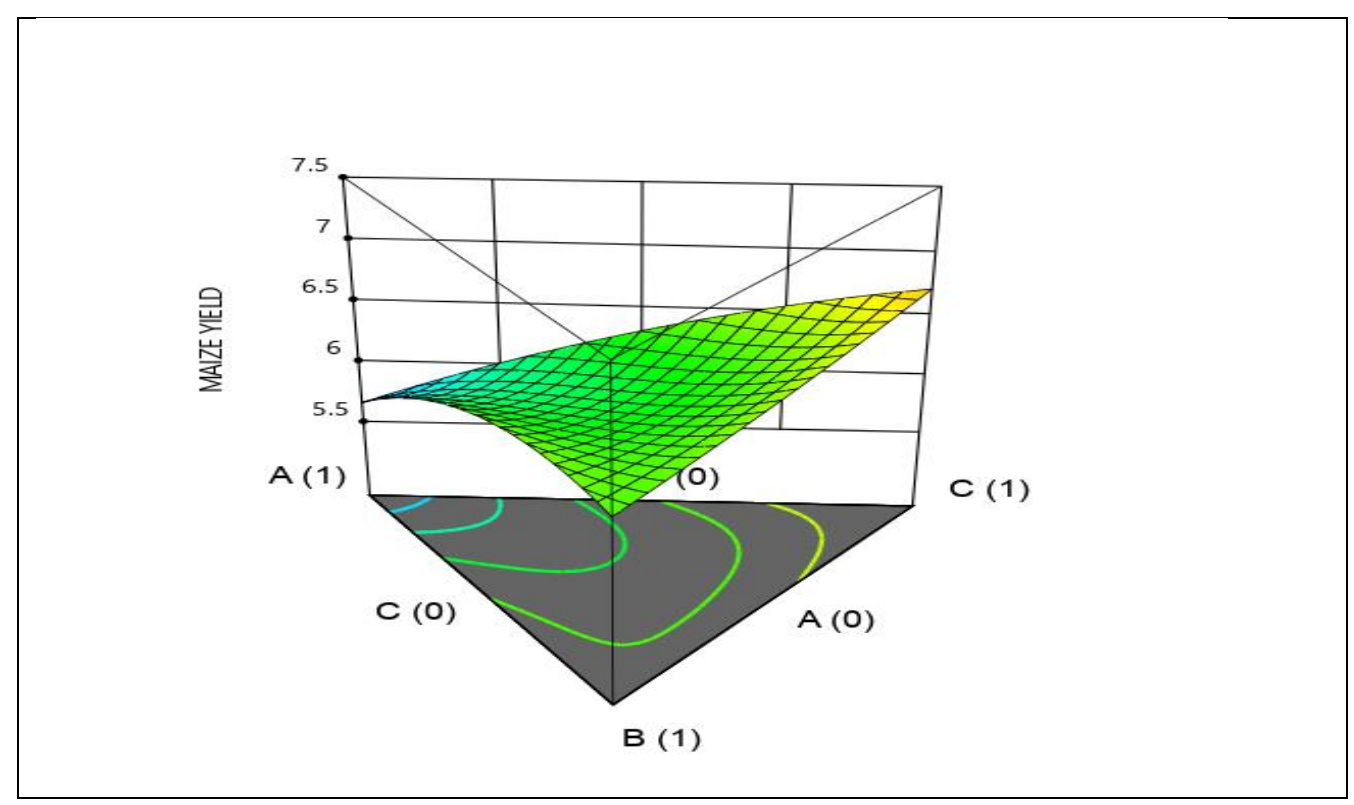

Figure 4: Response surface for maize yield as a function of farmyard manure (A), DAP (B) and sheep manure (C) at fixed Poultry manure at zero.

The figure above displays maize yield as a function of farmyard manure, DAP and sheep manure. It was observed that sheep manure was superior to the other two. The response surface corresponding to farmyard manure and DAP indicate that there was a slight increase in the yield though the synergy effect was lower than the effect from the sheep manure on the yield. In this case, the maximum predicted maize yield in terms of coded variables was $Y=6.7$ from a set of conditions; Farmyard manure $\left(X_{1}\right)=0, \operatorname{DAP}\left(X_{2}\right)=0$ and $\operatorname{Sheep}\left(X_{3}\right)=1$ when Poultry Manure $\left(\mathrm{X}_{4}\right)$ set at zero. 


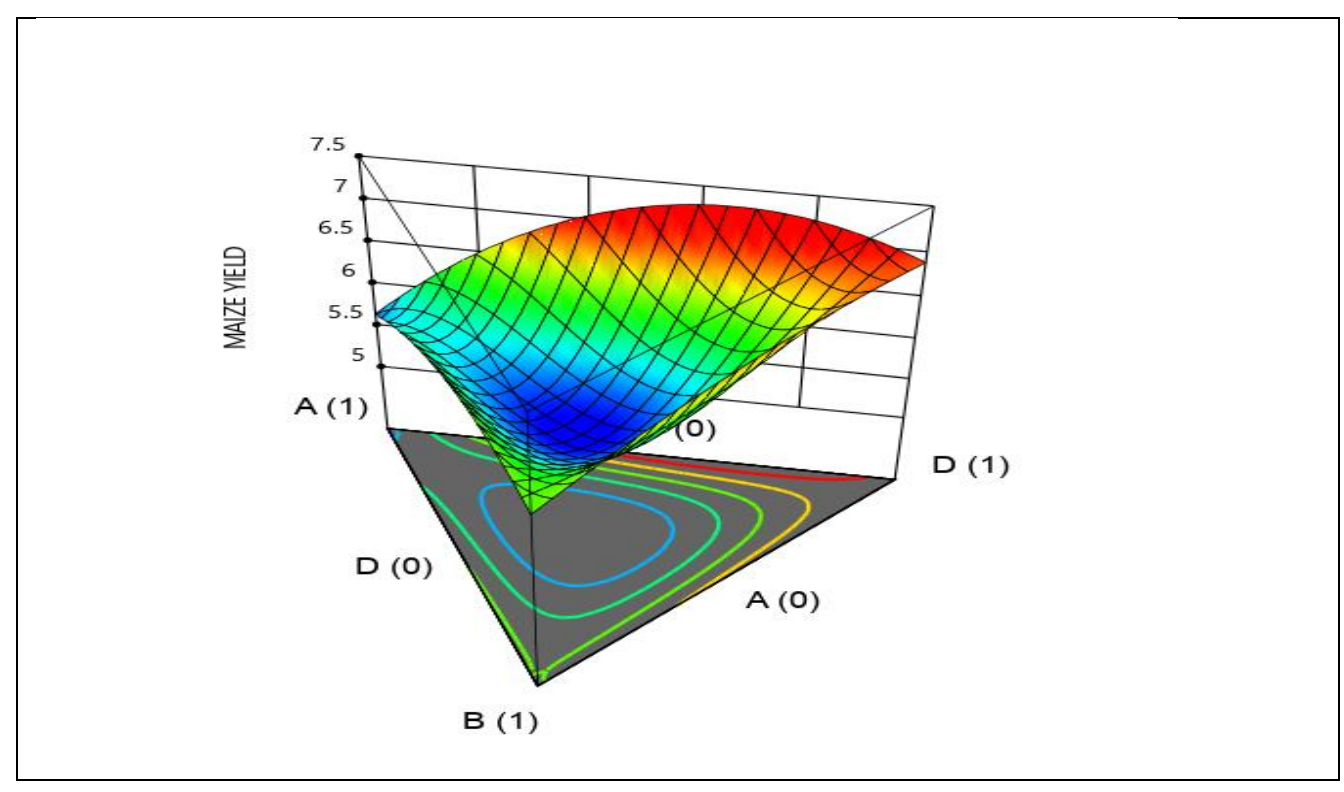

Figure 5: Response surface for maize yield as a function of farmyard manure (A), DAP (B) and poultry manure (D) at fixed sheep manure at zero.

The graph above shows the response surface for maize yield as a function of farmyard manure, DAP and poultry Manure. From the graph, the resultant yield for cubic blends exhibit low yields demonstrated by the presence of a depression on the plot. Nevertheless, for binary blends, the plot shows an improved yield as the poultry manure was increased. An optimal set was observed for farmyard and poultry blend. Hence the maximum predicted maize yield in coded form was found as $\mathrm{Y}=7.30227$ from the set of conditions; Farmyard manure $\left(\mathrm{X}_{1}\right)=0.3333$, DAP $\left(X_{2}\right)=0$, and Poultry Manure $\left(X_{4}\right)=0.6666$ when Sheep manure $\left(X_{3}\right)=0$.

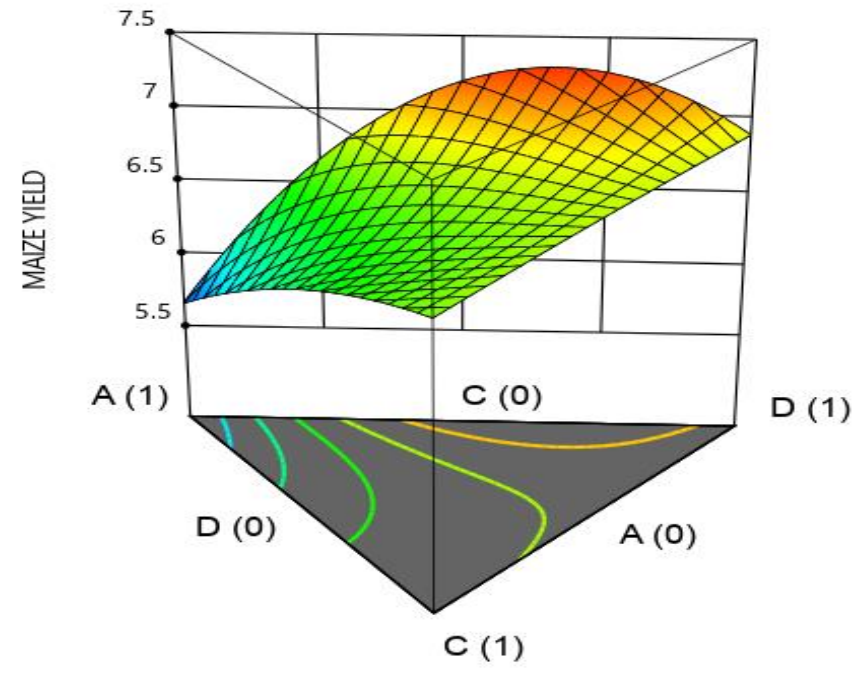

Figure 6: Response surface for maize yield as a function of farmyard manure (A), Sheep manure (C) and poultry manures(D) at fixed DAP at zero.

The graph above shows the response surface for maize yield as a function of farmyard manure, sheep manure and poultry Manure. The plot shows the lowest yield on farmyard pure blend and progressive increase as the proportions of either sheep or poultry or both are increased. However, the optimal set again is observed for farmyard and poultry blend with the maximum predicted maize yield $Y=7.30227$ from the set of conditions 
farmyard manure $\left(\mathrm{X}_{1}\right)=0.3333$, Sheep manure $\left(\mathrm{X}_{3}\right)=$ zero, and Poultry Manure $\left(\mathrm{X}_{4}\right)=0.6666$ when DAP $\left(\mathrm{X}_{2}\right)$ =zero.

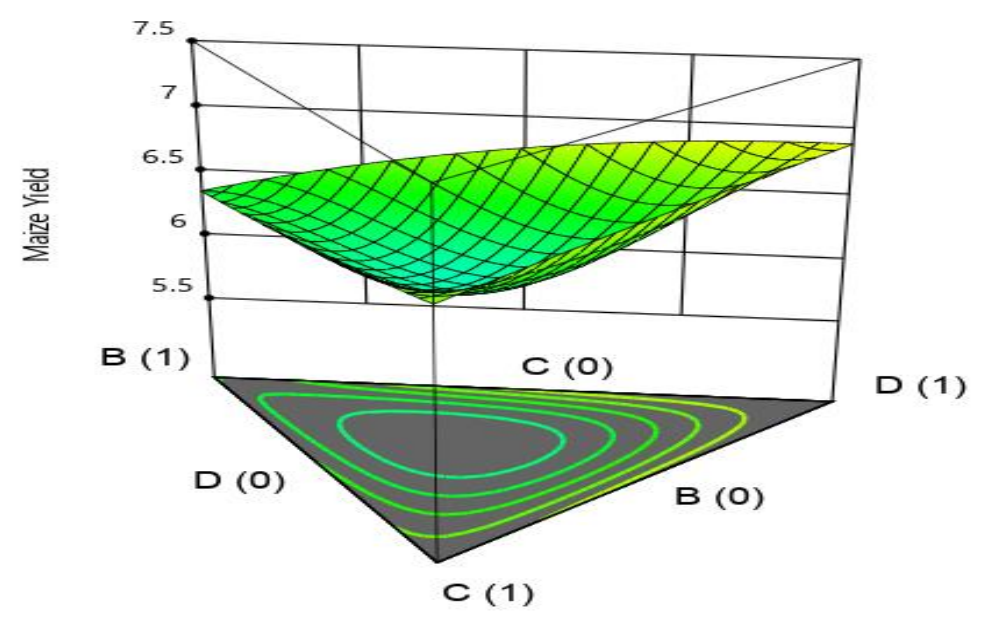

Figure 7: Response surface for maize yield as a function of DAP (B), Sheep manure(C) and poultry manure (D) at fixed farmyard manure (A) at zero.

The plot shows that the yield was superior for poultry as a single component than in any other areas where blending was involved. The maximum predicted Maize grain weight $(\mathrm{Y})=6.87727$, from the set of conditions; Farmyard manure $\left(\mathrm{X}_{1}\right)=0$, Sheep manure $\left(\mathrm{X}_{3}\right)=0$ and Poultry manure $\left(\mathrm{X}_{4}\right)=1$ when $\mathrm{X}_{1}$ is set at Zero.

\subsubsection{Summary table for optimal conditions for maize yield}

From the four graphs and contour plots, the study concluded that the optimal proportion for the maize yield was obtained at the following set of coded variables; farmyard manure $\left(\mathrm{X}_{1}\right)=1 / 3$ and Poultry manure $\left(\mathrm{X}_{4}\right)=2 / 3$ with a corresponding maize yield of 7.30227 as tabulated below.

Table 7: Optimal conditions for maximum maize yield

\begin{tabular}{llll}
\hline Variables & Components & Optimal Value (coded) & Actual Value \\
\hline $\mathbf{X}_{\mathbf{1}}$ & Farmyard & $1 / 3$ & 6.67 tons \\
$\mathbf{X}_{\mathbf{2}}$ & DAP & 0 & 0 \\
$\mathbf{X}_{\mathbf{3}}$ & Sheep Manure & 0 & 0 \\
$\mathbf{X}_{\mathbf{4}}$ & Poultry manure & $2 / 3$ & 1.3467 tons \\
$\mathbf{Y}$ & Maize yield & 7.30227 & 12.17 tons \\
\hline
\end{tabular}

\subsection{CONCLUSION}

This study involves the use of mixture experiment in determination of the existence of synergism in fertilizer components in the production of maize crops. The study found the four-factor simplex lattice design to be suitable in investigating the interactive effects of the fertilizer on the maize grain production. However, the statistical model formulated was useful in predicting the effect of single, binary and tertiary components on dependent variable (output). The study concluded that all single components were statistical significant at $95 \%$ confident interval. Furthermore, the study found that there was a synergetic effect in two blends namely farmyard manure and DAP and the other blend is farmyard manure and poultry manure. Nevertheless, the maximum maize yield was realized under optimal set of conditions from a blend of farmyard manure and poultry manure. The study concludes that a mixture of farmyard manure and poultry manure as suitable in enhancing maize production up to a maximum maize yield of $\mathbf{1 2 . 1 7}$ tons/Ha from a blend of $\mathbf{6 . 6 7 t o n / h a}$ of farmyard manure and 1.3467 tons/ha of poultry manure. 


\subsection{ACKNOWLEDGEDMENT}

The authors grateful acknowledge the support received from University of Kabianga research and teaching farm. The authors are thankful to Alfred the farm attendant and Agronomist Jonah for their support, guidance and provision of farm materials that were necessary in completion of the experiment.

\subsection{REFERENCES:}

Cornell, J.A. (1990). Experiments with mixture Designs, models and analysis of mixture data. (Second Edition). John Willey and sons, New York.

De Jager A., Nandwa S.M. and Okoth P.F.(1998). Monitoring Nutrient flows and economic performance in African farming system (NUTMON) Iv. Linking Nutrient balances and economic performance in three Districts in Kenya Agriculture ecosystems and environment 71 (1998) 37-48.

Kenya Agricultural Research Institute KARI- Njoro (2013 Annual Report).Validation and Promotion of soil fertility improvement technologies for enhancement of maize production in the central rift valley district (Maina Murage, Ndembei, N.W.and Kirui M.).

Montgomery D.C. (2000), Design and analysis of experiments fifth edition. John Wiley and Sons New York. NY.

Muriithi D. K. (2017). The optimization of multiple responses of water melon to organic manure using response surface methodology ,European international Journal of science and technology 2017, Vol. 6(2):52-70.

Scheffe', H. (1958). Experiments with mixture. Journal of the Royal Statistical Society Series, B, 20, No.2, 344-360. 